\title{
CARACTERÍSTICAS BIOMÉTRICAS E FÍSICO-QUÍMICAS DO FRUTO, MORFOLOGIA DA SEMENTE E DA PLÂNTULA DE Averrhoa carambola L. (OXALIDACEAE) ${ }^{1}$
}

\author{
MARCIA TEREZINHA RAMOS DE OLIVEIRA², PEDRO AMORIM BERBERT ${ }^{3}$, ROZIMAR DE CAMPOS PEREIRA4 \\ HENRIQUE DUARTE VIEIRA ${ }^{5}$, VINICIUS OLIVEIRA CARLESSO ${ }^{6}$
}

\begin{abstract}
RESUMO - Este trabalho foi realizado com o objetivo de caracterizar os frutos, estudar a morfologia externa e interna das sementes e ilustrar o desenvolvimento de plântulas e de plantas jovens de Averrhoa carambola. Os frutos foram distribuídos em três categorias, de acordo com o estádio de maturação (maduros, intermediários e verdes), e em três subcategorias de acordo com o tamanho (grande, médio e pequeno). Para a caracterização dos frutos determinaram-se as dimensões, a massa, o número de sementes, a cor, o pH e os teores de água e de sólidos solúveis totais (SST) da polpa. Para a caracterização morfológica das sementes foi medido o comprimento, a largura, a espessura, a massa e determinada as dimensões do endosperma, cotilédone e eixo hipocótilo radicular. Determinou-se, também, a massa de 1000 sementes. Os frutos maduros e grandes apresentam dimensões e teor de SST próximos aos encontrados em frutos comerciais, no entanto, com menor luminosidade e maior intensidade de cor, com predominância do alaranjado. O endosperma é o órgão de reserva das sementes, que exibem cotilédones de cor branca, com leve tom esverdeado nos bordos; a germinação é epígea e a protrusão da raiz primária iniciase 21 dias após a semeadura. Os dados obtidos na avaliação das características das sementes apresentam desvios-padrão baixos, indicando que os valores medidos podem ser usados em estudos taxonômicos e na análise da germinação.
\end{abstract}

Termos para indexação: germinação, desenvolvimento pós-seminal, planta jovem.

\section{BIOMETRY AND PHYSICAL-CHEMICAL CHARACTERIZATION OF Averrhoa carambola L. (OXALIDACEAE) FRUIT AND SEED AND SEEDLING MORPHOLOGY}

\begin{abstract}
The objective of this study was to describe the fruit and also study external and internal seed morphology, as well as the development of seedlings and young plants of Averrhoa carambola $\mathrm{L}$. The fruit lot was divided into three categories according to fruit maturity (ripe, half ripe, unripe), and into three subcategories according to fruit size (large, intermediate and small). The parameters used to characterize the fruit were the dimensions, seed weight and color; the fruit pulp was characterized by its moisture content, total soluble solids content and $\mathrm{pH}$. The external seed morphology was described by its dimensions and weight whereas the internal
\end{abstract}

\footnotetext{
${ }^{1}$ Submetido em 24/05/2010. Aceito para publicação em 12/09/2010.

${ }^{2}$ Tecnóloga em Horticultura, Doutoranda do Programa de Pós-graduação em Produção Vegetal da Universidade Estadual do Norte Fluminense Darcy Ribeiro (UENF), CEP 28013-602, Campos dos Goytacazes, RJ. E-mail: maroli@uenf.br
}

${ }^{3}$ Eng. Agrícola, Ph.D., Professor Associado, Laboratório de Engenharia Agrícola (LEAG/UENF). E-mail: pberbert@uenf.br
${ }^{4}$ Eng. Florestal, DS, Professor Adjunto - UFRB. Cruz das Almas. E-mail: rozimarcp@uol.com.br

${ }^{5}$ Eng Agr, DS, Professor Associado, Laboratório de Fitotecnia (LFIT/ UENF). E-mail: henrique@uenf.br

${ }^{6}$ Eng Agr, Doutorando do Programa de Pós-graduação em Produção Vegetal (LEAG/UENF). E-mail: carlesso@uenf.br 
morphology was described by the sizes of the endosperm, the cotyledon and root-hypocotyl axes. The weight of 1000 seeds was also determined. Fruit classified as large and ripe had dimensions and a total soluble solids content similar to those mentioned in the literature, albeit with less Hunter luminosity (L), and a higher intensity of color, predominantly orange. Endosperm is the seed's nutritional reserve and contains white cotyledons with a pale green rim. Germination is epigeous, and radicle protrusion occurs 21 days after sowing. The high degree of homogeneity of the parameters studied may make them suitable for use in taxonomic studies and an analysis of germination of the species.

Index terms: germination, post-seminal development, star-fruit.

\section{INTRODUÇÃO}

A caramboleira (Averrhoa carambola L.), frutífera pertencente à família Oxalidaceae, é originária do sudoeste asiático e hoje se encontra dispersa em regiões tropicais e em áreas quentes de regiões subtropicais de todos os continentes (Lennox e Ragoonath, 1990; Nakasone e Paull, 1998). Foi introduzida no Brasil no início do século XVIII e atualmente é cultivada em pomares domésticos em todo o País, exceto em regiões frias ou sujeitas a geadas, havendo, entretanto, poucas plantações comerciais (Crane, 1994; Donadio et al., 2001). É uma árvore de porte pequeno ( $3 \mathrm{a} 5 \mathrm{~m}$ ) a médio ( 8 a $9 \mathrm{~m}$ ), mas pode chegar a $15 \mathrm{~m}$ de altura aos 25 anos de idade, que é considerado seu período de vida útil. A planta é perene, de crescimento lento, com tronco encurtado, torcido e áspero, ramos flexíveis, com porte piramidal, quando jovem, e copa densa e arredondada, quando adulta, com 6 a $7 \mathrm{~m}$ de diâmetro. $\mathrm{O}$ fruto é muito valorizado devido à sua aparência e formato pouco usuais, geralmente com cinco saliências longitudinais, raramente quatro ou seis, ainda que alguns trabalhos citem de duas a oito. O fruto de caramboleira é baga oblonga, amarelo-brilhante e glabro quando maduro; quando fatiado, transversalmente, apresenta o formato singular de uma estrela (Crane, 1994; Epstein, 2000; Donadio et al., 2001; Lorenzi e Matos, 2002; Bastos, 2004; Ferreira Jorge et al., 2005).

De acordo com Salles (1987), a identificação das plantas no estádio juvenil conduz a três direções principais: contribuir para um melhor entendimento da biologia da espécie, ampliar os estudos taxonômicos e auxiliar em trabalhos de levantamento ecológico, principalmente nos aspectos de regeneração por sementes em condições naturais e na ocupação e estabelecimento ambiental por qualquer espécie. Além disso, os aspectos morfológicos das plântulas podem ser empregados tanto na identificação de plantas de uma determinada região, quanto para facilitar a interpretação de testes de germinação em laboratório. O conhecimento das estruturas da semente também é relevante para a obtenção de informações sobre o armazenamento, viabilidade e métodos de semeadura. Taxonomicamente a semente pode e deve ser utilizada para caracterização de famílias, de gêneros e até de espécies, visto que apresentam pouca variação em função do meio (Gunn, 1972; Toledo e Marcos Filho, 1977).

Ferreira Jorge et al. (2005) caracterizaram as sementes de carambola como sendo anátropas, de coloração marrom, comprimento de 1,3 cm, alongadas, sendo observadas duas em cada lóculo. De acordo com Donadio et al. (2001), as sementes perdem rapidamente a viabilidade depois de extraídas dos frutos. No entanto, Oliveira et al. (2009) mostraram que sementes de carambola com teor de água entre 6 e $8 \%$ podem manter seu percentual de germinação por até 180 dias, quando armazenadas a $10{ }^{\circ} \mathrm{C}$.

Este trabalho foi desenvolvido com os objetivos de determinar as características biométricas e físicoquímicas do fruto e descrever a morfologia da semente e plântula de carambola.

\section{MATERIAL E MÉTODOS}

Este trabalho foi realizado no Centro de Ciências e Tecnologias Agropecuárias da Universidade Estadual do Norte Fluminense Darcy Ribeiro (UENF), Campos dos Goytacazes, RJ. Para determinação das 
características biométricas e físico-químicas do fruto, como comprimento, diâmetro equatorial, massa, número de sementes, cor, $\mathrm{pH}$ e teor de sólidos solúveis totais, foram utilizados 600 frutos do grupo doce, colhidos em 20 matrizes na localidade de Brejo Grande, distrito de Campos dos Goytacazes. Apesar dos esforços realizados para a identificação da cultivar de acordo com os aspectos morfológicos da folha (Andrade e Martins, 2007), não foi possível precisar a cultivar utilizada nesse estudo.

Dos 600 frutos colhidos, 200 foram destinados igualmente para cada uma das três categorias, de acordo com o estádio de maturação (maduros, intermediários e verdes). De cada uma das categorias, foram criadas três subcategorias de acordo com o tamanho (grande, médio e pequeno), cada uma contendo cerca de 65 frutos. Para mensuração do comprimento e diâmetro, em relação aos maiores eixos longitudinal e transversal dos frutos, respectivamente, utilizou-se paquímetro digital Digimess $150 \mathrm{~mm}$. Para a determinação da massa dos frutos in natura, os frutos inteiros foram lavados e secos e em seguida pesados em balança Sartorius BP $4100 \mathrm{~S}$ com acurácia de $0,01 \mathrm{~g}$. Quanto às avaliações físicoquímicas, foram utilizadas as metodologias listadas a seguir:

Coloração externa dos frutos: a determinação dos parâmetros relativos à cor externa foi feita de acordo com os procedimentos descritos por McGuirre (1992), empregando-se colorímetro Minolta, modelo CR 300, medindo-se em três pontos distintos na região medial das saliências dos frutos; a média desses resultados foi expressa em ângulo de cor $\left(\mathrm{h}^{\circ}\right)$, por meio dos parâmetros de Hunter (L, $a, b)$ e pela intensidade da cor, dada pelo parâmetro C (Chroma). O ângulo de cor $\left(\mathrm{h}^{\circ}\right)$ é uma medida da tonalidade e é representado por valores entre zero e $360^{\circ}$. Ângulos entre zero e $90^{\circ}$ são representados pelas cores vermelhas, laranjas e amarelas; de 90 a $180^{\circ}$ são as amarelas, as amarelo-verdes e as verdes; de 180 a $270^{\circ}$ são as verdes, as verde-azuladas e as azuis; de 270 a $360^{\circ}$ são as azuis, as púrpuras, as magentas e novamente as vermelhas. Na escala de Hunter, o índice $\mathrm{L}$ mede a luminosidade, que varia de zero, para amostras totalmente pretas, a 100 para amostras totalmente brancas. O índice $a$ mede a variação da cor verde (sinal negativo) à vermelha (sinal positivo). $O$ índice $b$ mede a variação da cor azul (sinal negativo) à amarela (sinal positivo). Valores de a e b iguais a zero equivalem à cor cinza. As leituras de todos os parâmetros relativos à cor foram feitas nos frutos in natura depois de lavados e enxugados com papel toalha.

Teor de água dos frutos: Foi determinado em três repetições para frutos em cada um dos estádios de maturação, independentemente do tamanho e empregando-se três frutos por repetição. A preparação das amostras para determinação do teor de água foi feita utilizando-se triturador Tecnal, modelo Turratec TE102. Depois de pesadas em balança analítica Sartorius BL 210S, as amostras $(5 \mathrm{~g})$ foram secas em estufa a vácuo Nova Ética $440 \mathrm{D}$, a $70{ }^{\circ} \mathrm{C}$, por $6 \mathrm{~h}$, sob pressão de $13,3 \mathrm{kPa}$ (AOAC, 1990a). A determinação foi feita imediatamente depois da recepção dos frutos no laboratório, o que ocorreu, em média, 2 h após o término da colheita.

Teor de sólidos solúveis totais (SST) dos frutos: Foi realizado utilizando seis repetições de frutos verdes, intermediários e maduros, independentemente do tamanho. O teor de SST, expresso em ${ }^{\circ}$ Brix foi determinado pelo método proposto pela AOAC (1990b) para amostras de fruta in natura. Uma alíquota da polpa triturada foi colocada sobre o prisma de um refratômetro portátil Atago, modelo HSR 500, procedendo à leitura direta do índice refratométrico indicado pelo aparelho.

pH da polpa dos frutos: Utilizaram-se seis repetições de frutos verdes, intermediários e maduros, independentemente do tamanho. A polpa dos frutos in natura foi primeiramente homogeneizada com microtriturador de aço inox, com cabeçote do tipo dentado com hélice. Para determinação do $\mathrm{pH}$, cerca de $3 \mathrm{~g}$ da amostra fresca triturada foram diluídas em $20 \mathrm{~mL}$ de água destilada e o $\mathrm{pH}$ da suspensão foi determinado diretamente em potenciômetro Digimed, modelo DM 20 (Pregnolatto e Pregnolatto, 1985).

O estudo da morfologia das sementes, de plântulas e plantas jovens da caramboleira foi feito de acordo com os procedimentos descritos a seguir. Para a execução dessa etapa do trabalho, foram utilizadas apenas as sementes provenientes de 20 frutos maduros.

Aspectos morfológicos das sementes: para a retirada das sementes, os frutos colhidos foram lavados em água corrente, cortados no sentido longitudinal, paralelamente às saliências. Em seguida, as sementes foram retiradas manualmente e transferidas para uma peneira com malha de aço, onde foram lavadas em água corrente, sendo levemente friccionadas umas às outras e também contra a malha, para a retirada do arilo. As sementes foram enxugadas com papel toalha para remoção da água superficial. Utilizaram-se 50 
sementes, com teor de água de 32,5\% b.u., medindose, individualmente, o comprimento (do ápice à base), a largura (do lado direito ao esquerdo) e a espessura (da parte dorsal à ventral). Depois da determinação das dimensões externas, as sementes foram abertas com estilete, do ápice à base, ao longo da rafe, para medição das dimensões do endosperma, do cotilédone e do eixo hipocótilo-radicular.

Massa de 1000 sementes: foi determinada de acordo com os procedimentos descritos em Brasil (2009), empregandose balança Sartorius modelo BL 210S, com grau de acurácia de $0,1 \mathrm{mg}$. A partir da massa das amostras de 1000 sementes foi calculado o número de sementes por grama.

Aspectos morfológicos da plântula: a realização dessa etapa do experimento foi feita a partir do monitoramento da germinação das sementes em estufa Eletrolab, modelo 122FC. O teste de germinação foi realizado empregando-se quatro subamostras de 50 sementes, em rolo de papel germiteste com quantidade de água equivalente a 2,5 vezes a sua massa e colocadas em germinador regulado a $20^{\circ} \mathrm{C}$, para o período noturno, e $30{ }^{\circ} \mathrm{C}$, para o período diurno, com fornecimento de luz por $8 \mathrm{~h}$. As avaliações dos estádios de desenvolvimento da plântula foram realizadas a cada sete dias, a partir do $14^{\circ}$ dia, durante 84 dias. Considerou-se como plântula o indivíduo no estádio de desenvolvimento entre a protrusão da raiz primária e a emissão da primeira folha, quando passou a ser considerada planta jovem (Sobrinho e Siqueira, 2008).

Aspectos morfológicos da planta jovem: para a descrição da morfologia e ilustração do desenvolvimento da planta jovem, foram semeadas 100 sementes em tubetes de $115 \mathrm{~cm}^{3}$, utilizando-se substrato comercial Plantmax e irrigando-se duas vezes ao dia por 110 dias; o cultivo foi realizado em ambiente protegido com tela sombrite $50 \%$. Adicionalmente, foram feitas três aplicações de solução nutritiva a cada 10 dias a partir dos 60 dias da semeadura; a composição da solução se encontra na Tabela 1. Para a descrição morfológica foram utilizadas as plantas jovens e, dentre estas, apenas uma foi utilizada para ilustração, analisando-se o tipo de germinação, forma e cor da raiz.

TABELA 1. Composição da solução nutritiva padrão aspergida em três ocasiões no substrato utilizado no teste de germinação das sementes de carambola em ambiente protegido.

\begin{tabular}{|c|c|c|c|}
\hline Macronutrientes & $\mathrm{mL} \cdot \mathrm{L}^{-1}$ & Micronutrientes $^{\underline{2} /}$ & $\mathrm{mg} . \mathrm{L}^{-1}$ \\
\hline $\mathrm{Ca}\left(\mathrm{NO}_{3}\right)_{2} 4 \mathrm{H}_{2} \mathrm{O}\left(2 \mathrm{~mol} \cdot \mathrm{L}^{-1}\right)$ & 1,50 & $\mathrm{ZnSO}_{4} 7 \mathrm{H}_{2} \mathrm{O}$ & 578 \\
\hline $\mathrm{KNO}_{3}\left(2 \mathrm{~mol} . \mathrm{L}^{-1}\right)$ & 2,00 & $\mathrm{CuSO}_{4} 5 \mathrm{H}_{2} \mathrm{O}$ & 250 \\
\hline MAP $\left(1 \mathrm{~mol} . \mathrm{L}^{-1}\right)$ & 0,25 & $\mathrm{MnSO}_{4} \mathrm{H}_{2} \mathrm{O}$ & 845 \\
\hline $\mathrm{MgSO}_{4}\left(1 \mathrm{~mol} . \mathrm{L}^{-1}\right)$ & 1,00 & $\mathrm{KCl}$ & 3728 \\
\hline Fe EDTA (25g.L $\left.\mathrm{L}^{-1}\right)$ & 1,00 & $\left(\mathrm{NH}_{4}\right)_{6} \mathrm{Mo}_{7} \mathrm{O}_{24} 4 \mathrm{H}_{2} \mathrm{O}$ & 88 \\
\hline $\mathrm{H}_{3} \mathrm{BO}_{3}(25 \mathrm{mM})$ & 1,00 & & \\
\hline$\left(\mathrm{NH}_{4}\right)_{2} \mathrm{SO}_{4}\left(1 \mathrm{~mol} . \mathrm{L}^{-1}\right)$ & 0,25 & & \\
\hline Micronutrientes $^{\underline{1} /}$ & 1,00 & & \\
\hline
\end{tabular}

A solução principal contém $1,0 \mathrm{~mL} \cdot \mathrm{L}^{-1}$ de micronutrientes ${ }^{1 /}$, concentração preparada de acordo com micronutrientes ${ }^{2}$.

Teor de água das sementes: o teor de água das sementes foi determinado seguindo as recomendações propostas pelas Regras para Análise de Sementes (Brasil, 2009), empregando-se temperatura de $105^{\circ} \mathrm{C}$, por $24 \mathrm{~h}$.

\section{Análise estatística}

Os dados experimentais relativos à caracterização biométrica e físico-química do fruto foram avaliados por meio de análise de variância. Os valores médios foram comparados aplicando-se o teste Tukey, adotando-se o nível de 5\% de probabilidade.

\section{RESULTADOS E DISCUSSÃO}

\section{Biometria e aspectos físico-químicos do fruto}

$\mathrm{Na}$ Tabela 2 constam os resultados referentes aos valores médios de massa, comprimento e diâmetro equatorial dos frutos, assim como os valores relativos ao 
número de sementes por fruto e das características físicoquímicas da carambola, como os teores de água e de sólidos solúveis totais, o $\mathrm{pH}$ e os parâmetros que definem a coloração externa do fruto.

TABELA 2. Valor médio e desvio padrão* dos parâmetros biométricos e características físico-químicas de frutos de carambola in natura.

\begin{tabular}{|c|c|c|c|}
\hline \multirow{2}{*}{ Parâmetro avaliado e tamanho do fruto } & \multicolumn{3}{|c|}{ Estádio de maturação } \\
\hline & Verde & Intermediário & Maduro \\
\hline \multicolumn{4}{|l|}{ Massa (g) } \\
\hline Pequeno & $31,32 \pm 4,14 \mathrm{bB}$ & $43,79 \pm 7,03 \mathrm{cA}$ & $39,24 \pm 6,88 \mathrm{cAB}$ \\
\hline Médio & $60,51 \pm 8,78 \mathrm{aA}$ & $58,04 \pm 7,25 \mathrm{bA}$ & $59,66 \pm 6,68 \mathrm{bA}$ \\
\hline Grande & $62,03 \pm 6,05 \mathrm{aB}$ & $82,25 \pm 12,10 \mathrm{aA}$ & $78,39 \pm 10,03 \mathrm{aA}$ \\
\hline \multicolumn{4}{|l|}{ Comprimento $(\mathrm{cm})$} \\
\hline Pequeno & $6,0 \pm 0,3 \mathrm{cC}$ & $6,9 \pm 0,4 \mathrm{cA}$ & $6,5 \pm 0,5 \mathrm{cB}$ \\
\hline Médio & $7,9 \pm 0,6 \mathrm{bA}$ & $7,7 \pm 0,3 \mathrm{bA}$ & $7,7 \pm 0,4 \mathrm{bA}$ \\
\hline Grande & $8,3 \pm 0,4 \mathrm{aB}$ & $8,8 \pm 0,5 \mathrm{aA}$ & $8,4 \pm 0,3 \mathrm{aB}$ \\
\hline \multicolumn{4}{|l|}{ Diâmetro equatorial $(\mathrm{cm})$} \\
\hline Pequeno & $3,9 \pm 0,1 \mathrm{bB}$ & $4,3 \pm 0,3 \mathrm{bA}$ & $4,0 \pm 0,4 \mathrm{cAB}$ \\
\hline Médio & $4,8 \pm 0,2 \mathrm{aA}$ & $4,5 \pm 0,3 \mathrm{bA}$ & $4,7 \pm 0,3 \mathrm{bA}$ \\
\hline Grande & $5,1 \pm 0,1 \mathrm{aB}$ & $5,6 \pm 0,9 \mathrm{aA}$ & $5,3 \pm 0,3 \mathrm{aB}$ \\
\hline \multicolumn{4}{|l|}{ Número de sementes por fruto } \\
\hline Pequeno & $1,3 \pm 0,5 \mathrm{bA}$ & $1,2 \pm 0,4 \mathrm{bA}$ & $1,8 \pm 1,0 \mathrm{bA}$ \\
\hline Médio & $2,3 \pm 1,9 \mathrm{abA}$ & $2,6 \pm 2,2 \mathrm{aA}$ & $2,0 \pm 1,5 \mathrm{abA}$ \\
\hline Grande & $4,0 \pm 0,0 \mathrm{aA}$ & $3,6 \pm 2,1 \mathrm{aA}$ & $3,1 \pm 2,0 \mathrm{aA}$ \\
\hline Teor de água (\% b.u.) & $90,4 \pm 0,8 \mathrm{~A}$ & $91,0 \pm 0,5 \mathrm{~A}$ & $90,3 \pm 0,5 \mathrm{~A}$ \\
\hline Teor de SST $\left({ }^{\circ}\right.$ Brix $)$ & 4,5 a 6,0 & 5,2 a 6,3 & 6,4 a 9,0 \\
\hline $\mathrm{pH}$ & 3,6 & 3,8 & 4,3 \\
\hline \multicolumn{4}{|l|}{ Cor } \\
\hline $\mathrm{L}$ & 31,3 & 31,8 & 32,4 \\
\hline $\mathrm{a}$ & $-5,2$ & $-3,0$ & 5,4 \\
\hline $\mathrm{b}$ & 12,6 & 13,0 & 14,2 \\
\hline $\mathrm{C}$ & 24,1 & 23,9 & 27,3 \\
\hline $\mathrm{h}^{\mathrm{o}}$ & 107,9 & 100,3 & 74,7 \\
\hline
\end{tabular}

${ }^{*}$ Médias seguidas por letras distintas, minúsculas nas colunas e maiúsculas nas linhas, diferem entre si, pelo teste de Tukey aos 5\% de probabilidade.

Considerando a totalidade de frutos avaliados, ou seja, frutos em todos os estádios de maturação e tamanho, verificou-se, em relação ao comprimento, que os valores variaram entre 5,6 e 9,7 cm, com média de 7,6 \pm 0,9 $\mathrm{cm}$. Quanto ao diâmetro equatorial dos frutos, obtevese média de 4,7 $\pm 0,6 \mathrm{~cm}$ e valores mínimo e máximo de 3,4 e $7,8 \mathrm{~cm}$. Araújo e Minami (2001) observaram variações médias de comprimento entre 8,6 e $11,7 \mathrm{~cm}$ ao avaliarem as características de 4500 carambolas coletadas em seis ocasiões, no período entre 1997 e 1999, de 15 matrizes localizadas em pomar comercial em Mirandópolis, SP; os diâmetros médios dos frutos variaram entre 4,7 e $6,5 \mathrm{~cm}$. Oliveira et al. (1989a) observaram variação no comprimento entre 6,0 e 9,4 cm 
ao avaliarem as características de 100 frutos de carambola provenientes de Estação Experimental localizada em Maracanaú, CE. Teixeira et al. (2001) caracterizaram seis cultivares de carambola, avaliando 20 frutos por cultivar, em Bebedouro, SP; o comprimento variou entre 9,4 e 11,4 cm e o diâmetro entre 5,6 e 6,8 cm. Observa-se, portanto, que os frutos avaliados no presente trabalho apresentaram maior intervalo de variação, em termos de comprimento e diâmetro, do que aqueles mencionados na literatura. Araújo e Minami (2001) observaram a existência de relação linear positiva $\left(\mathrm{R}^{2}=0,99\right)$ entre o comprimento e o diâmetro dos frutos de carambola, ou seja, à medida que o comprimento aumentava ocorria o mesmo com o diâmetro. No presente trabalho, a reta de mínimos quadrados que se ajustou ao conjunto de valores de comprimento e diâmetro dos frutos não apresentou coeficiente de determinação tão satisfatório $\left(\mathrm{R}^{2}=0,69\right)$, indicando maior irregularidade dos frutos quanto ao formato em relação ao observado por Araújo e Minami (2001).

Em relação à massa do fruto in natura, considerando todos os estádios de maturação e tamanhos de frutos, o valor médio foi de $58,1 \pm 17,4$ g, com variação no intervalo entre 25,5 e 100,2 g. No estudo de Araújo e Minami (2001), a menor e maior médias foram de 64,9 e 127,1 g, respectivamente. Oliveira et al. (1989a) relataram valores entre 28,4 e 94,9 g. Os resultados obtidos por Teixeira et al. (2001) revelaram que os frutos da cultivar Nota-10 foram os mais pesados $(135,8 \mathrm{~g})$, ao passo que aqueles da cultivar Golden Star foram os mais leves $(89,1 \mathrm{~g})$. Verifica-se, portanto, que no presente experimento, considerando-se os limites inferiores dos parâmetros biométricos, foram utilizados frutos menores e mais leves que aqueles descritos na literatura.

Observa-se, na Tabela 2, que não houve diferença significativa entre os valores médios de massa, comprimento, diâmetro e número de sementes por fruto, para os frutos classificados como de tamanho médio, para todos os estádios de maturação avaliados. Para as subcategorias "pequeno" e "grande”, o grau de homogeneidade dos frutos verdes, intermediários e maduros, quanto aos parâmetros mencionados, não foi tão alto quanto o observado para frutos classificados como médios.

Os lóculos localizam-se nas saliências do fruto e contêm de zero a cinco sementes; intervalo de variação mais amplo que o relatado por Donadio et al. (2001), que afirmaram que o número de sementes por lóculo varia de zero a três; entretanto, apesar de cada fruto conter cinco lóculos e cada lóculo poder apresentar cinco sementes, o número máximo de sementes por fruto foi de sete, com média de 2,3 $\pm 1,7$. Ferreira Jorge et al. (2005) observaram a presença de duas sementes em cada lóculo. Foi possível inferir que, para cada um dos estádios de maturação, houve relação diretamente proporcional entre o tamanho do fruto e o número de sementes nele contidas. A frequência de distribuição do número de sementes por fruto evidenciou que a maioria contém apenas uma única semente. Esse resultado contrasta com os valores mencionados na literatura consultada, que relata maior número médio de sementes por fruto (Donadio et al., 2001; Teixeira et al., 2001; Ferreira Jorge et al., 2005).

Os resultados relativos ao teor de sólidos solúveis totais (SST) mostraram, como esperado, aumento dessa variável à medida que o fruto amadurece. Os valores, para frutos maduros, variaram entre 6,4 e 9,0 ${ }^{\circ} \mathrm{Brix}$. Teixeira et al. (2001) observaram variação de 7,9 a $10,3{ }^{\circ}$ Brix para frutos maduros de seis cultivares de carambola. Araújo e Minami (2001) mencionaram variação na média do teor de SST entre 4,9 e 6, $6{ }^{\circ}$ Brix em 270 frutos dos tipos doce e ácido, coletados de 15 caramboleiras. Para frutos da espécie Averrhoa bilimbi L., os valores observados por Araújo et al. (2009) variaram entre 2,4 e 3,2 ${ }^{\circ}$ Brix. Considerando-se todos os estádios de maturação, observase que o intervalo de variação do teor de SST das carambolas utilizadas no presente experimento (4,5 a 9,0 $\left.{ }^{\circ} \mathrm{Brix}\right)$ é similar àquele descrito na literatura e consideravelmente maior que os valores encontrados para Averrhoa bilimbi. $\mathrm{O} \mathrm{pH}$ dos frutos variou entre 3,6 (verdes) e 4,3 (maduros), indicando frutos menos ácidos que aqueles estudados por Araújo e Minami (2001), com média de pH, dependendo da caramboleira, variando entre 1,6 e 3,3, e muito menos ácidos que Averrhoa bilimbi que apresentou valor de pH variando entre 1,1 e 1,6 de acordo com o estádio de maturação (Araújo et al., 2009). O elevado teor de água observado ( $90,6 \%$ b.u.) é comparável aos valores obtidos por diversos autores citados por Oliveira et al. (1989b), que variaram no intervalo de 89,9 a 91,7\% b.u.

Os parâmetros de Hunter L, a e b, o ângulo de cor h ${ }^{\circ} \mathrm{e}$ a intensidade da cor $\mathrm{C}$ de carambolas in natura, utilizadas no presente trabalho, também estão apresentados na Tabela 2. Os valores obtidos para a luminosidade L (31,3 $\leq \mathrm{L} \leq 32,4)$ indicaram que os frutos não apresentavam tendência ao escurecimento no momento da retirada das sementes. Araújo e Minami (2001) e Teixeira et al. (2001) relataram valores de luminosidade no intervalo $46,4 \leq \mathrm{L} \leq$ 50,9 e $43,8 \leq \mathrm{L} \leq 52,4$, respectivamente, ou seja, os limites 
inferiores desses intervalos são maiores que o maior valor de L obtido no presente trabalho. Esse resultado evidencia que, em seus estudos para caracterização dos frutos, aqueles autores avaliaram carambolas com maior apelo comercial em termos de brilho ou luminosidade.

Quanto à variação de cor do verde ao vermelho, medida pelo parâmetro a, constatou-se, como esperado, que os frutos verdes apresentaram os menores valores e os maduros, os maiores. Quanto ao parâmetro b, que mede a variação do azul (-b) ao amarelo (+b), observou-se que a presença da cor amarela aumentou à medida que o estádio de maturação avançou do verde ao maduro. Portanto, considerando-se apenas o plano a-b no diagrama de Hunter (McLellan et al., 1995), verificou-se que a cor das carambolas classificadas como verdes e intermediárias encontra-se no quadrante II do diagrama, ou seja, entre verdes e amarelo-esverdeadas; a cor dos frutos classificados como maduros encontra-se no quadrante I, com predominância da cor alaranjada.

Em relação ao parâmetro $C$, que indica a intensidade de cor, os valores variaram entre $24,1 \leq \mathrm{C} \leq 27,3$. Araújo e Minami (2001) e Teixeira et al. (2001) observaram valores de intensidade de cor em frutos de carambola nos intervalos de $20,6 \leq \mathrm{C} \leq 28,9$ e $17,5 \leq \mathrm{C} \leq 25,9$, respectivamente, ou seja, os valores obtidos nesse trabalho mostram o emprego de frutos com cores, em geral, mais intensas que aqueles citados na literatura.
Os valores do ângulo $\mathrm{h}^{\circ}$, que indicam a tonalidade ou matiz, variaram entre $74,7 \leq h^{\circ} \leq 107,9$; os maiores valores foram observados em frutos verdes e os menores, em maduros. Valores de ${ }^{\circ}$ maiores que 90 indicam que ainda estão ocorrendo alterações do verde para o amarelo na cor do fruto. Valores entre 45 e 90 (frutos maduros) indicam que está ocorrendo variação entre o amarelo e o alaranjado. Os valores observados por Araújo e Minami (2001) e Teixeira et al. (2001) encontram-se nos seguintes intervalos, respectivamente: $107,1 \leq \mathrm{h}^{\circ} \leq 113,3$ e $100,0 \leq$ $\mathrm{h}^{\mathrm{o}} \leq 115,0$, mostrando o emprego de frutos de tonalidade mais amarelo-esverdeada.

\section{Aspectos morfológicos das sementes e da germinação}

Os valores médio, mínimo e máximo das dimensões externas comprimento (ápice à base), largura (lado direito ao esquerdo) e espessura (da parte dorsal à ventral) e o valor médio da massa da semente encontram-se na Tabela 3. O tegumento das sementes é de coloração marrom-clara, com superfície brilhante e cerosa; quando recém-retiradas dos frutos, as sementes encontram-se envoltas em arilo gelatinoso (Figura 1). A cor das sementes está de acordo com a descrição de Ferreira Jorge et al. (2005), entretanto as sementes analisadas nesse experimento apresentaram menor comprimento. A massa de 1000 sementes foi de 40,9 g, para teor de água de 9,7\% b.u, o que, proporcionalmente, resulta em 24 a 25 sementes por grama.

TABELA 3. Valor médio e desvio padrão, mínimo e máximo das dimensões externas e da massa de semente de carambola.

\begin{tabular}{lccc}
\hline Parâmetro biométrico externo da semente & Valor médio & Valor mínimo & Valor máximo \\
\hline Comprimento $(\mathrm{mm})$ & $10,14 \pm 0,82$ & 8,69 & 12,45 \\
Largura $(\mathrm{mm})$ & $5,26 \pm 0,34$ & 4,06 & 6,00 \\
Espessura $(\mathrm{mm})$ & $2,22 \pm 0,13$ & 1,86 & 2,69 \\
Massa $(\mathrm{g})$ & $0,062 \pm 0,008$ & 0,038 & 0,082 \\
\hline
\end{tabular}

NaTabela4encontram-seasdimensõesdoendosperma, cotilédone e eixo hipocótilo-radicular. Os cotilédones são de cor branca com um leve tom esverdeado nos bordos (Figura 2); o eixo hipocótilo-radicular é cilíndrico, com diâmetro médio de $0,74 \pm 0,11 \mathrm{~mm}$ e comprimento de $1,57 \pm 0,18 \mathrm{~mm}$. A ilustração característica das partes constituintes da semente, incluindo o eixo hipocótiloradicular, cotilédone, endosperma e tegumento, encontrase na Figura 2. A protrusão da raiz primária ocorreu a partir do $21^{\circ}$ dia do teste de germinação (Figura 3A); na
Figura 3B encontra-se a ilustração de uma plântula aos 42 dias do teste de germinação. Para efeito comparativo, mostra-se, na Figura 4A, a ilustração de uma plântula aos 63 dias do teste de germinação. Foi possível observar que a protrusão da raiz primária ocorre em intervalo de tempo bem maior que o observado para a maioria das sementes de espécies frutíferas, pois somente aos 42 dias é possível observar as primeiras raízes secundárias e são necessários 63 dias para que as raízes primaria e secundárias estejam mais desenvolvidas. 


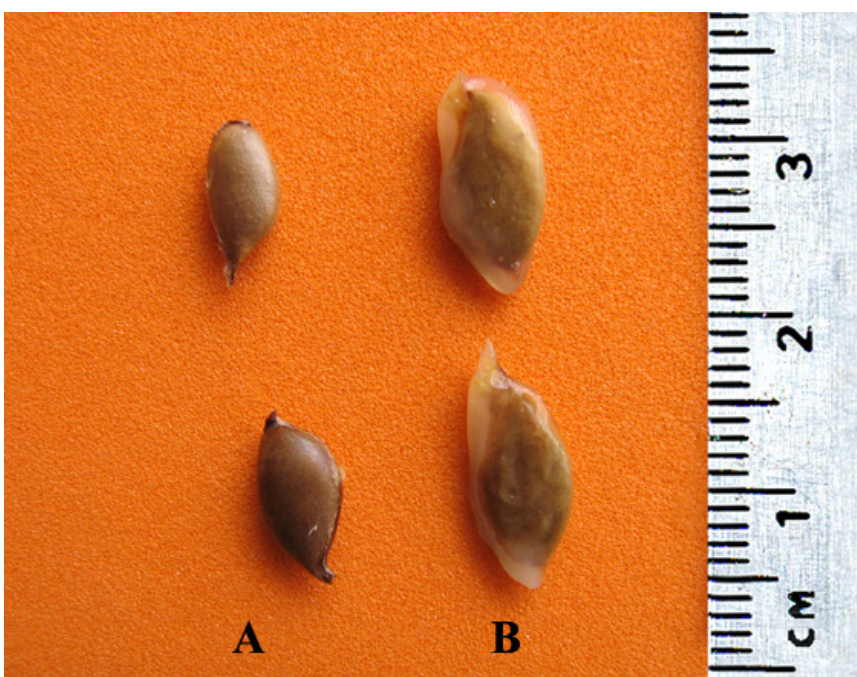

FIGURA 1. Aspecto externo da semente de Averrhoa carambola L., sem arilo (A) e com arilo (B).

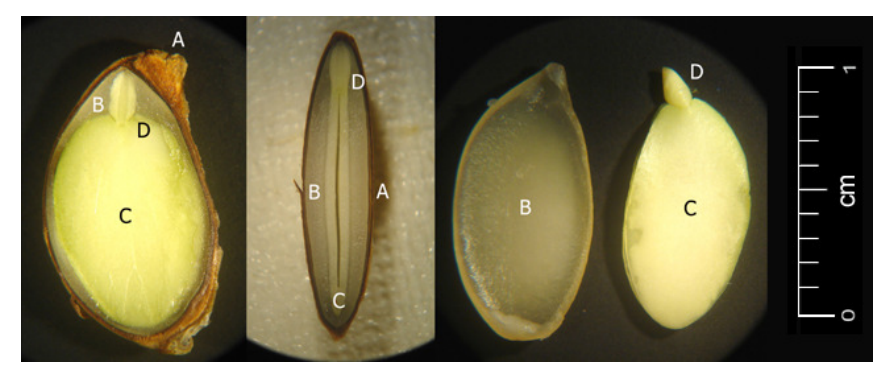

FIGURA 2. Aspecto interno da semente de Averrhoa carambola L. Tegumento (A), endosperma (B), cotilédones (C) e eixo hipocótilo radicular (D)
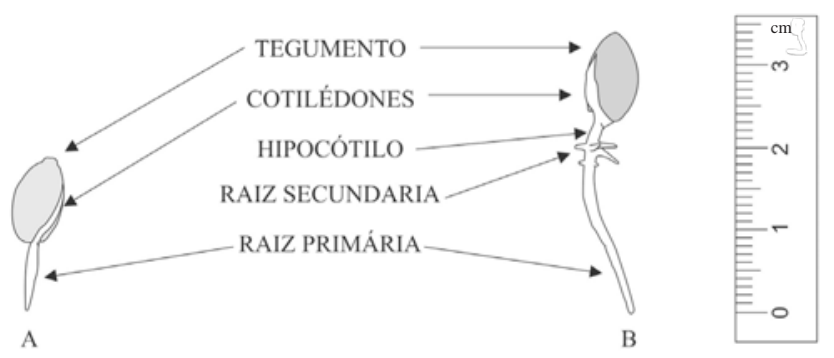

FIGURA 3. Plântula de $A$. carambola com 28 (A) e 42 (B) dias após a semeadura.
TABELA 4. Valor médio e desvio padrão, mínimo e máximo das dimensões do endosperma, cotilédones e embrião da semente de carambola.

\begin{tabular}{lccc}
\hline $\begin{array}{l}\text { Parâmetro biométrico } \\
\text { interno da semente e } \\
\text { dimensão }\end{array}$ & $\begin{array}{c}\text { Valor } \\
\text { médio }\end{array}$ & $\begin{array}{c}\text { Valor } \\
\text { mínimo }\end{array}$ & $\begin{array}{c}\text { Valor } \\
\text { máximo }\end{array}$ \\
\hline Endosperma & & \\
\hline Comprimento (mm) & $8,48 \pm 0,55$ & 7,32 & 9,85 \\
Largura (mm) & $5,27 \pm 0,39$ & 4,06 & 6,00 \\
Espessura (mm) & $0,59 \pm 0,06$ & 0,51 & 0,83 \\
\hline \multicolumn{4}{c}{ Cotilédone } \\
\hline Comprimento (mm) & $6,87 \pm 0,94$ & 1,20 & 8,12 \\
Largura (mm) & $4,19 \pm 0,27$ & 3,60 & 4,68 \\
Espessura (mm) & $0,26 \pm 0,02$ & 0,21 & 0,32 \\
\hline
\end{tabular}

\begin{tabular}{lccc}
\hline \multicolumn{4}{c}{ Eixo hipocótilo radicular } \\
\hline Comprimento (mm) & $1,57 \pm 0,18$ & 1,17 & 1,92 \\
Diâmetro (mm) & $0,74 \pm 0,11$ & 0,44 & 0,95 \\
\hline
\end{tabular}

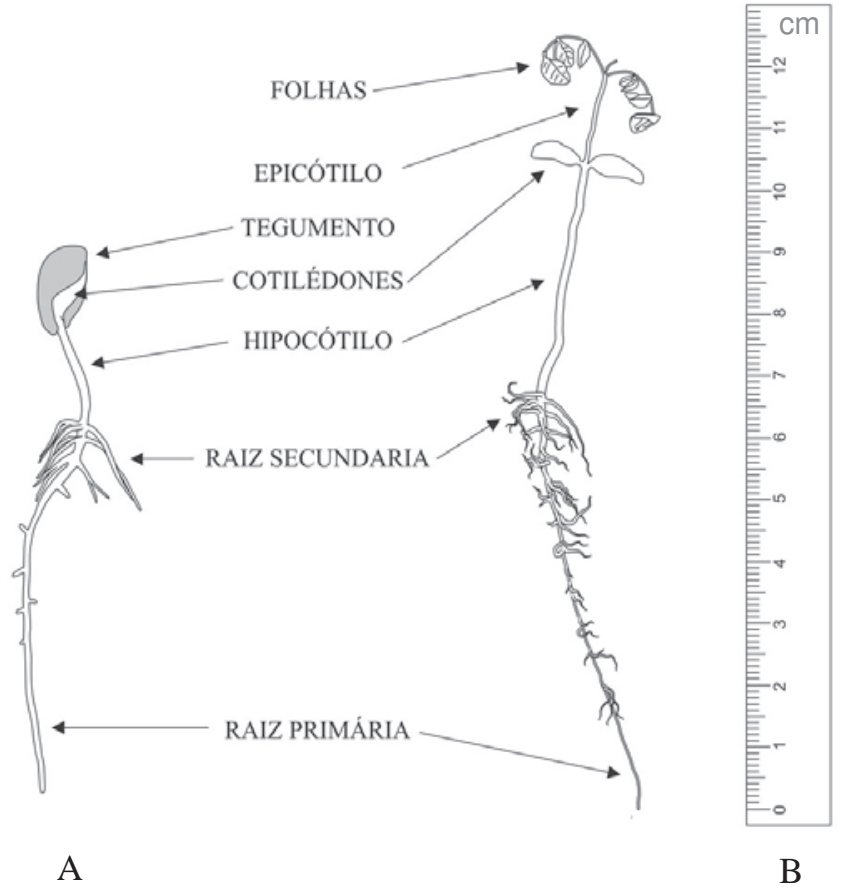

FIGURA 4. Plântula de $A$. carambola com 63 dias (A) e planta jovem com 84 dias (B) de desenvolvimento após a semeadura 


\section{Aspectos morfológicos da planta jovem}

A ilustração de uma planta jovem de A. carambola no $84^{\circ}$ dia do teste de germinação é mostrada na Figura 4B. A emergência ocorreu de 25 a 60 dias (com média de 40 dias) depois da semeadura; a raiz primária é cilíndrica, de coloração branca, com crescimento linear. A plântula, ao emergir, apresenta cotilédones ainda envoltos pelo tegumento, que se desprende da planta jovem quando o comprimento do eixo hipocótilo atinge, em média, 2,0 cm. A germinação é epígea e os cotilédones, que apresentam coloração verde, se abrem e permanecem na planta até cerca de 110 dias depois da semeadura. O epicótilo atinge, em média, $1,2 \mathrm{~cm}$ de comprimento até a emissão das primeiras folhas. Ao final desse período, as plantas apresentavam, em média, quatro pares de folhas dispostas alternadamente ao redor do caule; as folhas são compostas ( 2 a 5 pares de folíolos), imparipenadas, completas, ovaladas ou oval-lanceoladas, pecioladas e pinadas, de coloração roxa-bronzeada, quando jovens; essa caracterização da planta jovem está de acordo com as características da planta descrita por Epstein (2000) e Donadio et al. (2001). O sistema radicular é formado pela raiz principal e raízes secundárias e terciárias, apresentando coloração marrom clara. Assim observa-se que o teste de germinação para as sementes de carambola deve ter longa duração, para que se possa observar uma plântula normal, já que a primeira contagem só se justificaria aos 21 dias após a semeadura, quando se pode observar a protrusão da raiz primária de algumas sementes.

\section{CONCLUSÕES}

Os frutos maduros e grandes apresentam parâmetros biométricos e teor de SST próximos aos valores encontrados em frutos comerciais, no entanto com menor acidez, menor luminosidade e maior intensidade de cor, com predominância do alaranjado.

As sementes (24 a 25 por grama) são de coloração marrom clara e encontram-se envoltas em arilo gelatinoso. O endosperma translúcido é o órgão de reserva. Os cotilédones são de cor branca com leve tom esverdeado nos bordos; a germinação é epígea e a protrusão da raiz primária inicia-se 21 dias após a semeadura.

As dimensões e massa das sementes, e os parâmetros biométricos relativos ao endosperma, cotilédones e embrião das sementes apresentam desvios-padrão baixos, indicando que os valores medidos podem ser usados em estudos taxonômicos e na análise da germinação.

\section{AGRADECIMENTOS}

Os autores agradecem o apoio financeiro oferecido pelas seguintes instituições: CAPES, CNPq, FAPERJ, FINEP e International Foundation for Science (IFS) e a Sra. Louise Dulce Ulup Andersen pela confecção das ilustrações.

\section{REFERÊNCIAS}

ANDRADE, R.A.; MARTINS, A.B.G. Aspectos morfológicos de folhas na diferenciação de variedades de carambola. Revista Brasileira de Fruticultura, v.29, n.2, p.386-388. 2007. http://www.scielo.br/pdf/rbf/v29n2/36. pdf

ASSOCIATION OF OFFICIAL ANALYTICAL CHEMISTS. AOAC. Method 934.06: Moisture in dried fruits: Final action. Arlington, 1990a.

Method 932.12: solids (soluble) in fruits and fruit products: Refractometer method: Final Action. Arlington, 1990b.

ARAÚJO, E.R.; ALVES, L.I.F.; RÊGO, E.R.; RÊGO, M.M.; CASTRO, J.P.; SAPUCAY, M.J.L.C. Caracterização físico-química de frutos de biri-biri (Averrhoa bilimbi L.). Revista Biotemas, v.22, n.4, p.225-230. 2009. http://www. biotemas.ufsc.br/volumes/pdf/volume224/225a230.pdf

ARAÚJO, P.S.R.; MINAMI, K. Seleção de caramboleiras pelas características biométricas e físico-químicas dos frutos. Scientia Agricola, v.58, n.1, p.91-99. 2001. http:// www.scielo.br/scielo.php?script=sci_arttext\&pid=S0103$90162001000100015 \& \operatorname{lng}=\mathrm{pt} \& \mathrm{nrm}=\mathrm{iso} \& \mathrm{t} \operatorname{lng}=\mathrm{pt}$

BASTOS, D.C. A cultura da carambola. Revista Brasileira de Fruticultura, v.26, n.2, 2004. http://www.scielo.br/ scielo.php?script $=$ sci_arttext\&pid=S0100-2945200400020 0001\&lng=pt\&nrm $=$ iso \&tlng $=$ pt

BRASIL. Ministério da Agricultura, Pecuária e Abastecimento. Regras para análise de sementes. Ministério da Agricultura, Pecuária e Abastecimento. Secretaria de Defesa Agropecuária. Brasília, DF: Mapa/ ACS, 2009. 395p.

CRANE, J.H. The carambola. Fact Sheet HS-12.University of Florida: IFAS Extension, 1994. 6p. http://university.uog. edu/cals/people/PUBS/Carambol/MG26900.pdf 
DONADIO, L.C.; SILVA, J.A.A.; ARAÚJO, P.S.R.; PRADO, R.M. Caramboleira (Averrhoa carambola L.). Jaboticabal: SBF, 2001. 81p.

EPSTEIN, L. Carambola e fruta-pão: comunicação. Bahia Agrícola, v.4, n.1, p.14-18, 2000. http://www.seagri.ba.gov. br/RevBaAgr/rev_112000/carampao.htm

FERREIRA JORGE, L.I.; SILVA, A.M.; GONZALES, E.; ALONSO, A.C.B. Averrhoa carambola L. (Oxalidaceae) e Achras sapota L. (Sapotaceae) - elementos morfoanatômicos de orientação diagnóstica. Revista Brasileira de Farmácia, v.86, n.3, p.104-108. 2005. http://www. revbrasfarm.org.br/edicoes/pdf/2005/V86N32005/ pag104a108AVERRHOACARAMBOLA.pdf

GUNN, C.R. Seed collecting and identification. In: KOZLOWSKI, T.T. (Ed.). Seed biology. New York: Academic Press, v.1, p.1-20. 1972. http://www.ag.ohiostate.edu/ seedbio/\#

LENNOX, A.; RAGOONATH, J. Carambola and bilimbi. Fruits, v.45, n.5, p.497-501, 1990.

LORENZI, H.; MATOS, F.J.A. Plantas medicinais no Brasil: nativas e exóticas cultivadas. Nova Odessa: Instituto Plantarum de Estudos da Flora Ltda., 2002.544p.

McGUIRRE, R.G. Reporting of objective color measurements. HortScience, v.27, n.12, p.1254-1255, 1992.

McLELLAN, M.R.; LIND, L.R.; KIME, R.W. Hue angle determinations and statistical analysis for multiquadrant Hunter L,a,b data. Journal of Food Quality, v.18, n.3, p.235-240. 1995. http://www3.interscience.wiley.com/ journal/119245328/abstract

NAKASONE, H.Y.; PAULL, R. E. Tropical fruits. Oxon: CAB International, 1998. 445p.

OLIVEIRA, M.N.; MAIA, G.A.; GUEDES, Z.B.L.; GUIMARÃES, A.C.L.; FIGUEIREDO, R.W. Estudo das características físicas e do rendimento da carambola (Averrhoa carambola L.). Revista Ciência Agronômica, v.20, n.1-2, p.97-99. 1989a.
OLIVEIRA, M.N.; MAIA, G.A.; GUEDES, Z.B.L.; GUIMARÃES, A.C.L.; FIGUEIREDO, R.W. Características químicas e físico-químicas da carambola (Averrhoa carambola L.). Revista Ciência Agronômica, v.20, n.1-2, 129-133. 1989b.

OLIVEIRA, M.T.R.; BERBERT, P.A.; PEREIRA, R.C.; VIEIRA, H.D THIÉBAUT, J.T.L.; CARLESSO, V.O. Qualidade fisiológica e potencial de armazenamento de sementes de carambola. Revista Brasileira de Sementes, v.31, n.2, p. 236-244, 2009. http://www.scielo.br/scielo. php?script $=$ sci_arttext\&pid=S0101-31222009000200028 $\& \operatorname{lng}=\mathrm{pt} \& \mathrm{nrm}=\mathrm{iso} \& \operatorname{lng}=\mathrm{pt}$

PREGNOLATTO, W.; PREGNOLATTO, N.P. (Coord.) Normas analíticas do Instituto Adolfo Lutz: métodos químicos e físicos para análise de alimentos, 3.ed. São Paulo: Instituto Adolfo Lutz, 1985.

SALLES, H.G. Expressão morfológica de sementes e plântulas I. Cephalocereus fluminensis (Miq.) Britton \& Rose (Cactaceae). Revista Brasileira de Sementes, v.9, n.1, p.73-81, 1987. http://www.abrates.org.br/revista/ artigos/1987/v9n1/artigo05.pdf

SOBRINHO, S.P.; SIQUEIRA, A.G. Caracterização morfológica de frutos, sementes, plântulas e plantas jovens de mutamba (Guazuma ulmifolia Lam. - Sterculiaceae). Revista Brasileira de Sementes, v.30, n.1, p.114-120. 2008.

http://www.scielo.br/scielo.php?script=sci arttext\&pid $=$ S0101-31222008000100015\&lng $=$ pt\&nrm $=i$ so\&tlng $=\mathrm{pt}$

TEIXEIRA, G.H.A.; DURIGAN, J.F.; DONADIO, L.C.; SILVA, J.A.A. Caracterização pós-colheita de seis cultivares de carambola (Averrhoa carambola L.). Revista Brasileira de Fruticultura, v.23, n.3, p.546-550. 2001. http://www.scielo.br/scielo.php?script=sci arttext\&pid=S0100-29452001000300019\&lng=pt\&nrm $=\overline{\mathrm{i}}$ so\&tlng $=\mathrm{pt}$

TOLEDO, F.F.; MARCOS FILHO, J. Manual de sementes: tecnologia da produção. São Paulo: Agronômica Ceres, 1977. 224p. 